\title{
Hereditary angioedema type II combined with other allergic pathology-case report.
}

\author{
Svetlan Dermendzhiev¹, Tihomir Dermendzhiev², Angel Dzhambov ${ }^{3 *}$ \\ ${ }^{1}$ Second Department of Internal Medicine, Faculty of Medicine, Unit of Occupational Diseases and Toxicology, \\ Medical University of Plovdiv, Bulgaria \\ ${ }^{2}$ Department of Microbiology and Immunology, Faculty of Pharmacy, Medical University of Plovdiv, Bulgaria \\ ${ }^{3}$ Department of Hygiene and Ecomedicine, Faculty of Public Health, Medical University of Plovdiv, Bulgaria
}

\begin{abstract}
Hereditary Angioedema (HAE) is a rare disease, and its incidence varies across different populations. HAE belongs to a group of congenital immune deficiencies in the complement system. Deficiency of the C1-Esterase Inhibitor (C1-INH) is leading in the pathogenesis of type I HAE; in type II, which is less common, the level of C1-INH is normal or increased, but an incomplete inhibitor is produced. Various provoking factors can trigger a cascade of reactions leading to activation of the kinin system. Consequently, the clinical picture of angioedema unfolds. There is a wide range of swelling-inducing factors-e.g., mechanical, pharmacological, physical, occupational, toxic. However, according to the literature, there is insufficient clarity about the combination of HAE type II with other allergic diseases, specifically with bronchial asthma. In the current study, we present a clinical case that is expected to enrich the knowledge base and contribute to the specification of the diagnostic/therapeutic algorithm in such patients with combined immuno-allergic pathology.
\end{abstract}

Keywords: Allergy, Asthma, Urticaria, Angioneurotic edema.

Accepted on March 07, 2018

\section{Introduction}

It has been established that, in the majority of patients, asthma is allergic in nature [1]. It is among the officially accepted and most common phenotypes of the disease [2]. It is also known that allergic asthma is IgE-mediated, as is the pathogenesis of both angioedema and urticaria in most cases [1,3,4]. Mast cells have a major role in triggering the clinical manifestation of these diseases, and their degranulation (immune or nonimmune type) releases a number of mediators, such as histamine, tryptase, leukotrienes, PGD2, PAF and others. In addition to bronchoconstrictor activity, some of the released mediators also possess vasoactive properties. They cause dilatation of arterioles and increase in permeability of postcapillary venules [1]. These processes are at the root of the developing angioedema. Acute urticaria is an IgE-dominated process in which the leading role also belongs to the mast cells. The clinical manifestation of urticaria is predominantly related to histamine activation, which has been shown to be very important in immune regulation of acute and chronic allergic inflammation via four subtypes of receptors $[1,5,6]$. The aetiology and pathogenesis of hereditary angioedema (HAE) are also well understood $[1,3,4]$. In contrast to HAE type I, in which the deficiency of the $\mathrm{C} 1$-esterase inhibitor predominates, in HAE type II the inhibitor produced is functionally insufficient $[1,3,4]$. The aetiology, pathogenesis and clinical picture of asthma, angioedema and urticaria are considered separate immuno-allergic diseases [1,2,4,7].

This is not the case, however, when the symptoms of two or more allergic diseases occur simultaneously in the same patient, or when another concomitant immuno-allergic pathology is manifested on the background of an already diagnosed allergic disease.

Therefore, herein we present a case with the intent to broaden the knowledge of this issue of clinicians from a number of specialties (e.g., allergists, dermatologists, immunologists, pulmologists and toxicologists). This, in turn, could help increase the effectiveness of the therapeutic procedures undertaken in patients with a similar type of pathology.

\section{Material and Methods}

The source of information is patient's medical documentation, laboratory tests and results from consultations by allergologists, pulmologists, immunologists, as well as photographic material presented by the patient. Informed consent was obtained and all procedures adhered to the Helsinki Declaration. 


\section{Case Presentation}

\section{General and allergy targeted history}

A 50-y-old woman admitted urgently in the ward of Occupational diseases and allergology with a clinical manifestation of moderately severe asthma attack, accompanied by a massive angioneurotic swelling of the facial soft tissue and urticaria rash. The factor (allergen) triggering the acute pulmonary and skin-mucosal pathology was unknown.

HAE type II had been confirmed previously as evidenced by patient's medical documentation. The patient underwent a substitution treatment with a recombinant analogue of the human $\mathrm{C} 1$-esterase inhibitor $(\mathrm{C} 1-\mathrm{INH})$. During the preceding 2-y period, the levels of $\mathrm{C} 1-\mathrm{INH}$ and $\mathrm{C} 4$ were within the normal range. Thenceforth, she had been in clinical remission with regard to HAE. 6 y ago, she had been diagnosed with allergic bronchial asthma, which was defined as "moderate persistent" based on established clinical and functional criteria. Treatment included combined medication containing a fixed dose of systemic corticosteroids and a long acting beta 2agonist. In case of exacerbation, the patient had used an inhalation reliever from the group of fast-acting beta2-agonists.

The presented medical records provided no data on systemic and malignant diseases. There were no data on allergy to drugs, foods or insects. The patient did not take ACE inhibitors or other medication for which oedema and rash have been reported as adverse reactions. She was in contact with a cat and a dog at home. Patient had family history of asthma and angioedema.

On examination, patients' vital signs were normal. Physical examination showed massive, itchy oedema on her face, predominantly on the forehead and the eyelids with a soft texture. There were single hives on the face and neck (Figure 1). Systemic examination revealed shortness of breath, whistling breathing, episodic spastic cough, and expectoration of a scanty amount of dense slime. Chest examination showed hypersonic percussion tone, double-sided exacerbated vesicular breathing with extended expiration, and diffuse, scattered dry whistling rhonchi in both lungs.

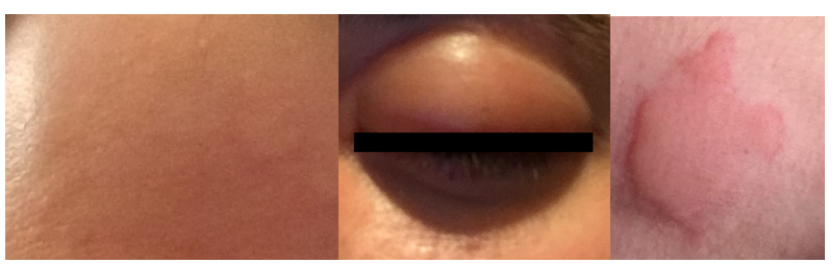

Figure 1. Sites of predilection of patient's angioedema-forehead, eyelid, neck.

The laboratory examinations and tests in pre-hospital and hospital care provided evidence for the immune-allergic aetiology of the diseases (Tables 1-3).

Table 1. Haematological and biochemical tests.

\begin{tabular}{|c|c|c|c|c|c|}
\hline Haematology & Reference value & $\begin{array}{l}\text { Differential } \\
\text { count }\end{array}$ & Reference value & Biochemistry & Reference value \\
\hline Haemoglobin-150.0 g/l & $140-180$ & Neutrophils-50.3\% & $42-70$ & Glucose-5.7 mmol/l & $2.8-6.1$ \\
\hline Red blood cells-4.88 T/l & $4.5-6$ & Lymphocytes-30.7\% & $22-48$ & TPROT-73.0 g/l & $60-83$ \\
\hline НСТ-0.399 & $0.40-0.54$ & Eosinophils-8.5\% & $0-6$ & Albumin-47.0 g/l & $35-52$ \\
\hline $\mathrm{MCH}-30.7 \mathrm{pg}$ & $27-33$ & Monocytes- $4.9 \%$ & $1-14.6$ & $\begin{array}{l}\text { Gamma-Glutamyl Transferase (GGT)-38 } \\
\text { U/I }\end{array}$ & $0-55$ \\
\hline MCV-81.8 fl & $82-98$ & Basophils- $0.5 \%$ & $0-2$ & $\begin{array}{l}\text { Aspartate Aminotransferase (AST)-29.0 } \\
\text { U/I }\end{array}$ & $0-36$ \\
\hline WBC-8.7 g/l & $3.5-10.5$ & & & Alanine Aminotransferase (ALT)-36.0 U/I & $0-45$ \\
\hline $\mathrm{MCHC}-326 \mathrm{~g} / \mathrm{l}$ & $300-360$ & & & Urea-7.2 mmol/l & $2.6-7.2$ \\
\hline PLT-223 g/l & $140-400$ & & & Creatinine-73.0 $\mu \mathrm{mol} / \mathrm{l}$ & $44-96$ \\
\hline $\mathrm{ESR}-8 \mathrm{~mm} / \mathrm{h}$ & 45689 & & & Alkaline Phosphatase (ALP)-78 U/l & $30-120$ \\
\hline $\begin{array}{l}\text { Table 2. Levels of serum immunog } \\
\text { tested before admission. }\end{array}$ & lobulin and con & plement fractions & \multicolumn{2}{|c|}{ C1 esterase inhibitor (Ag) } & $\begin{array}{l}\text { Serum } \quad 0.17-0.44 \\
g / l\end{array}$ \\
\hline Method & Result & Reference value & $\begin{array}{l}\text { C1 esterase } \\
\text { (functional) }\end{array}$ & inhibitor & $70-130 \%$ \\
\hline
\end{tabular}

Table 3. Levels of serum immunoglobulins and complement fractions tested after admission for current episode of angioedema.

\begin{tabular}{llll}
\hline Test & Method & Result & Reference value \\
\hline
\end{tabular}




\begin{tabular}{llll}
\hline Total IgE & ELISA & $80 \mathrm{IU} / \mathrm{ml}$ & $0-100 \mathrm{IU} / \mathrm{ml}$ \\
\hline $\mathrm{C} 3$ & $\begin{array}{l}\text { Nephelometr } \\
\mathrm{y}\end{array}$ & $1.28 \mathrm{~g} / \mathrm{l}$ & $0.9-1.8 \mathrm{~g} / \mathrm{l}$ \\
\hline $\mathrm{C} 4$ & $\begin{array}{l}\text { Nephelometr } \\
\mathrm{y}\end{array}$ & $0.26 \mathrm{~g} / \mathrm{l}$ & $0.1-0.4 \mathrm{~g} / \mathrm{l}$ \\
\hline $\mathrm{C} 1$ esterase inhibitor (Ag) & $\mathrm{RID}$ & $0.32 \mathrm{~g} / \mathrm{l}$ & Serum 0.17-0.44 g/l \\
\hline $\begin{array}{l}\text { C1 esterase inhibitor } \\
\text { (functional) }\end{array}$ & 1 & $70-130 \%$ \\
\hline
\end{tabular}

We performed skin-allergenic tests with a panel of indoor and outdoor allergens (grass pollen, wood birch allergen, microticks and allergens of animal origin) (Table 4). According to results from spirometry, the patient had moderate grade obstructing ventilatory disorder. Blood-gas analysis indicated arterial hypoxia, hyposaturation, and normal alkaline-acid equilibrium (Table 5).

Asthma exacerbation was managed after 5-d treatment with systemic corticosteroids, parenterally administered theophylline bronchodilator, and an inhalable fast-acting sympathomimetic. Antihistamines and H2-blockers were included in the complex treatment of concomitant skinmucosal allergic diseases, to counteract the H2-mediated receptor effects. The patient was dismissed in a good overall condition, with clinical, physical and functional improvement in lung status. Angioedema and urticaria underwent a complete remittance.

A therapeutic scheme for asthma control was specified. Further $\mathrm{H} 1$ and H2-blocker treatment was prescribed. Discontinuation of pet contact, dynamic clinical and functional pulmonary control and follow-up by an allergologist were recommended.

Based on the data from the general and specific allergic history, patient's subjective complaints, clinical picture, pulmonary and mucocutaneous allergic status, results of the laboratory examinations, and allergy tests, the definitive diagnosis was asthma with a predominantly allergic component-moderate severe bout with a concomitant episode of angioedema and urticaria.

Table 4. Patch test with a panel of animal and plant allergens.

\begin{tabular}{llll}
\hline Grass & 20 min & Micro-ticks & 20 min \\
\hline 688 (5 kinds of grass) & $10 / 5$ & 314 (D. farinae) & $(-)$ \\
\hline 687 (4 wheat) & $(-)$ & 315 (D. pteronissimus) & $12 / 5$ \\
\hline Trees & \multicolumn{3}{l}{ Allergens of animal origin } \\
\hline 696 (Beech) & $(-)$ & 507 (Cat) & $20 / 8$ \\
\hline 702 (Birch) & $8 / 3$ & 509 (Dog) & $14 / 5$ \\
\hline 701 (Willow) & $(-)$ & 506 (Feathers) & $(-)$ \\
\hline Weed & & Controls & $10 / 5$ \\
\hline 604 (Ambrosia) & $(-)$ & Positive control (histamine) & $(-)$ \\
\hline 605 (Plain wormwood) & $(-)$ & Negative control & \\
\hline 665 (Plantain herb) & $(-)$ & &
\end{tabular}

Table 5. Spirometry and blood-gas analysis.

\begin{tabular}{|c|c|c|c|c|c|}
\hline \multicolumn{3}{|l|}{ Spirometry } & \multicolumn{3}{|c|}{ Blood-gas analysis } \\
\hline Parameters & Actual levels & $\%$ (ECCS) & Parameters & Actual levels & Reference levels \\
\hline \multicolumn{6}{|l|}{ Dynamic } \\
\hline FVC (I) & 1.65 & 71.7 & $\mathrm{PaO}_{2} \mathrm{mmHg}$ & 62 & $>72.66$ \\
\hline FEV $1.0(\mathrm{I})$ & 0.83 & 42.4 & $\mathrm{HbO}_{2}(\%)$ & 0.9 & $>94.0$ \\
\hline FEV1/VC (\%) & 41.8 & 76.7 & $\mathrm{pH}$ & 7.42 & $7.36-7.44$ \\
\hline $\operatorname{PEF}(\mathrm{l} / \mathrm{s})$ & 2.42 & 44.1 & $\mathrm{SB}(\mathrm{meg} / \mathrm{l})$ & 25 & $22-26$ \\
\hline MEF $50 \%(\mathrm{I} / \mathrm{s})$ & & & $\mathrm{BE}(\mathrm{meg} / \mathrm{l})$ & 1 & $+/-2.3$ \\
\hline MEF $25 \%(\mathrm{l} / \mathrm{s})$ & & & $\mathrm{PaCO}_{2}$ & $38.0 \mathrm{mmHg}$ & $36-44$ \\
\hline \multicolumn{6}{|l|}{ Static } \\
\hline VC (I) & 1.98 & 86.8 & & & \\
\hline \multicolumn{6}{|l|}{ TLC (I) } \\
\hline ITGV/TLC (\%) & & & & & \\
\hline
\end{tabular}

\section{Discussion}

Asthma, angioedema and urticaria are among the most common allergic diseases in clinical practice. In vast majority of cases, all three conditions are considered IgE-mediated, which in some patients does not rule out interference with other types of allergic or non-immunological (pseudo-allergic) reactions and mechanisms. 
The unique features of the case presented by us can be summed-up as follows:

1. Combination of allergic asthma with urticaria and angioedema in the same person;

2. A combination of immunological and non-immunological mechanisms of established diseases;

3. The possibility of developing an allergic, IgE-mediated, angioedema in a patient with confirmed type II HAE, a disease related to the group of congenital immune deficiencies in the complement system.

Allergic aetiology of the oedema was suspected because of the clinical presentation and the good therapeutic response to conventional therapy with systemic corticosteroids and antihistamines that resulted in its complete remittance. Notably, the positive therapeutic response in patients with asthma does not always come soon after administration of corticosteroids. We speculate that the combination of several diseases characterized by different underlying pathogenetic mechanisms might be one of the factors resulting in the delayed response to treatment.

The combination of asthma, urticaria and angioedema in this particular case might not be a random event, given the positive atopy markers and the family history with allergic conditions. Blood eosinophilia, high levels of total IgE, positive skinallergy tests and the available family history supported the allergic aetiology of asthma. Patient's medical history, medical records, and immunological tests suggested HAE type II. However, the normal levels of antigenic and functional $\mathrm{C} 1$ $\mathrm{INH}$ and $\mathrm{C} 4$ found at the time of disease exacerbation indicated other type of angioedema. Hence, we cannot rule out the possibility that the patient suffered from a combination of various atopic manifestations-asthma, rhinitis, urticaria, angioedema. Moreover, the blood sampling was performed during the "acute attack", thus making the diagnosis of HAE less likely despite it being confirmed before patient's hospitalization. If the condition we observed was a HAE attached, it would have resolved spontaneously within 4-5 d. We had no information on whether genetic testing had ever been performed. As a final note, the considered possibility that the rash was erythema marginatum which may be misinterpreted as urticaria in patients with HAE [8].

\section{Conclusions}

It is possible for the same person to suffer from a combination of allergic diseases, different in their clinical picture. Mechanisms (allergic and non-allergic) which define onset and development of allergic diseases can also be observed in the same patient. The precise clarification of the aetiology and pathogenesis of any allergic disease is a prerequisite for achieving effective treatment in each particular case.

\section{Authors' Contributions}

S.D-conception and design of the study, drafting the manuscript, acquisition of data and informed consent, critical revision of the draft, final approval of the manuscript to be published; T.D and A.D-critical revision of the draft, final approval of the manuscript to be published.

\section{References}

1. Dimitrov V. Allergic diseases-principles, diagnosis and treatment. ARSO 2000.

2. Petkova E. Revision of GINA 2014-guide to the practitioner allergologist. Allerg Hypersens Asthma 2014; 1: 57.

3. Elissaveta N, Iskra A. Clinical immunology. Litse 2008; 138-140.

4. Krusheva B, Staevska M. Hereditary angioedema-the path to diagnosis and new therapeutic strategies. Allerg Hypersens Asthma 2016; 2: 11-23.

5. Petrov P, Staevska M. Allergies, hypersensitivity, asthma. Allerg Hypersens Asthma 2016; 2: 5-9.

6. Nijmeijer S, Leurs R, Vischer HF. Constitutive activity of the histamine H (1) receptor. Methods Enzymol 2010; 484: 127-147.

7. Cicardi M, Aberer W, Banerji A, Bas M, Bernstein JA, Bork K, Caballero T, Farkas H, Grumach A, Kaplan AP, Riedl MA, Triggiani M, Zanichelli A, Zuraw B. HAWK under the patronage of EAACI (European Academy of Allergy and Clinical Immunology). Classification, diagnosis, and approach to treatment for angioedema: consensus report from the Hereditary Angioedema International Working Group. Allergy 2014; 69: 602-616.

8. Rasmussen ER, de Freitas PV, Bygum A. Urticaria and prodromal symptoms including erythema marginatum in danish patients with hereditary angioedema. Acta Derm Venereol 2016; 96: 373-376.

\section{*Correspondence to}

Angel Dzhambov

Department of Hygiene and Ecomedicine

Faculty of Public Health

Medical University of Plovdiv

Bulgaria 